\title{
Analysis of Differences in ECG Characteristics for Different Types of Drivers under Anxiety
}

\author{
Yongqing Guo $\mathbb{D}^{1,2}$ Xiaoyuan Wang $\mathbb{D}^{2,3}$ Qing Xu, ${ }^{4}$ Quan Yuan $\mathbb{D}^{4},{ }^{4}$ Chenglin Bai, ${ }^{5}$ \\ and Xuegang (Jeff) Ban $\mathbb{1 0}^{6}$ \\ ${ }^{1}$ School of Transportation and Vehicle Engineering, Shandong University of Technology, Zibo 255049, China \\ ${ }^{2}$ Joint Laboratory for Internet of Vehicles, Ministry of Education-China Mobile Communications Corporation, \\ Tsinghua University, Beijing 100048, China \\ ${ }^{3}$ College of Electromechanical Engineering, Qingdao University of Science \& Technology, Qingdao 266000, China \\ ${ }^{4}$ State Key Laboratory of Automotive Safety and Energy, School of Vehicle and Mobility, Tsinghua University, \\ Beijing 100084, China \\ ${ }^{5}$ School of Physics Science and Communication Engineering, Liaocheng University, Liaocheng 252000, China \\ ${ }^{6}$ Department of Civil and Environmental Engineering, University of Washington, Seattle, WA, USA
}

Correspondence should be addressed to Xiaoyuan Wang; wangxiaoyuan@qust.edu.cn

Received 23 December 2020; Accepted 7 August 2021; Published 24 August 2021

Academic Editor: Hui Yao

Copyright ( 2021 Yongqing Guo et al. This is an open access article distributed under the Creative Commons Attribution License, which permits unrestricted use, distribution, and reproduction in any medium, provided the original work is properly cited.

\begin{abstract}
Anxiety is a complex emotion characterized by an unpleasant feeling of tension when people anticipate a threat or negative consequence. It is regarded as a comprehensive reflection of human thought processes, physiological arousal, and external stimuli. The actual state of emotion can be represented objectively by human physiological signals. This study aims to analyze the differences of ECG (electrocardiogram) characteristics for various types of drivers under anxiety. We used several methods to induce drivers' mood states (calm and anxiety) and then conducted the real and virtual driving experiments to collect driver's ECG signal data. Physiological changes in ECG during the experiments were recorded using the PSYLAB software. The independent sample $t$-test analysis was conducted to determine if there are significant differences in ECG characteristics for different types of drivers in anxious state during driving. The results show that there are significant differences in ECG signal characteristics of drivers by gender, age, and driving experience, in time domain, frequency domain, and waveform under anxiety. Our findings of this study contribute to the development of more intelligent and personalized driver warning system, which could improve road traffic safety.
\end{abstract}

\section{Introduction}

According to the statistics, more than $90 \%$ of traffic accidents are caused at least in part by human mistakes $[1,2]$, of which many errors result from drivers' negative emotional motivations such as anxiety, anger, and contempt. Driver's emotion as a psychological response has a substantial effect on the cognitive processes, including driver's perception, judgment, action, and behavior. Therefore, it is of great significance to identify driver's psychological and physiological characteristics in emotional states, in order to create safe and efficient driving.
Human emotions have a huge impact on how we live. The choices we make and the actions we take are influenced by the different types of emotions that we experience. There have been numerous studies to investigate the complex interactions between human emotion and physiological response in social, cultural, and economic fields, including household income [3], cultural diversity [4], physical health $[5,6]$, purchasing consumption $[7,8]$, Internet application [9], and environmental impact [10-12]. For example, Jaeger et al. [10] found that anxious emotion makes people want to eat more spicy snacks and single snack intake compared to their calm state. The study by Zhang et al. [7] and Wang 
et al. [8] suggested that high brightness evokes people's positive emotions and low brightness evokes people's negative emotions.

In the transportation field, researchers and scholars have conducted the studies of the correlation between emotional state and driving behavior and explored the influence of human-vehicle-environment factors toward driver' mood [13-15]. For example, while driving, driver's anxious emotion is more likely to be induced by environmental factors such as noisy and high arousal sound [14], low road visibility [16], and driver' factors such as less driving experience [17].

Emotional states are combinations of psychological arousal and physiological response. Human emotions result in physical and physiological changes that influence behavior through autonomic nervous responses, such as electrocardiogram $[18,19]$, respiration frequency $[20,21]$, pulse [22], skin electricity [23, 24], electromyogram [25], and skin temperature [26]. Existing research focuses on the impact of human emotion on the ECG signal properties. For example, a study by $\mathrm{Ba}$ et al. showed that emotion is correlated with skin resistance, heart rate, and breathing rate [27]. Takahashi et al. [28] found that the heartbeat interval becomes shorter and the ratio of low frequency band to high frequency band becomes higher in anger than in calm. Herrero-Fernández [29] found that the QT interval variability of ECG waveform is positively associated with the level of anger, and the RR interval variability of ECG waveform is negatively associated with the level of anger.

The detection and warning systems for traffic safety based on drivers' ECG signals have received increasing attention. Isikli Esener [30] recognized drivers' distress level using subspace-based feature extraction on ECG signals and other physiological measurements. Balasubramanian and Bhardwaj [31] used a noncontact ECG measurement approach to determine the fatigue levels of drivers. Zhao et al. [32] measured drivers' mental fatigue according to their ECG signals. Gromer et al. [33] applied a low-cost ECG sensor to detect drivers' drowsiness, by extracting the main ECG parameters including heart rate, QRS-complex, and heart rate variability. Taherisadr et al. [34] proposed an ECG-based driver distraction detection system using convolutional neural networks.

In conclusion, there have been few attempts in the past to analyze the influence of driver's emotions on their behavioral based on physiological signals. Hence, it is essential for transportation researchers to identify driver's ECG characteristics in emotional states to gain a deep understanding of how driver's emotions affect their behavior and reactions. This study focuses on examining the differences of ECG characteristics for various types of drivers in anxious state during driving.

\section{Research Method}

2.1. Participants. This study included 27 male drivers and 21 female drivers (age range: $22-50 \mathrm{y}$; mean age: $33.4 \mathrm{y}$ ). Participants were classified into three groups according to their driving propensities, which were determined by the propensity questionnaire [1]. The three groups were extraversion, middle type, and introversion, respectively. In this study, if drivers drove less than 10,000 kilometers, they would be considered as novice drivers, experienced drivers otherwise. Participants drove approximately $14,000 \mathrm{~km}$ miles on average. Prior to the experiment, they were told not to take any drugs that affect the brain and nervous system within one week and not to have tea, coffee, and wine that affect the mood and mental state within 48 hours. Moreover, they were asked to avoid any vigorous and high-intensity workout. Researchers provided a detailed description of the experimental design to the participants. Summary information of participants is presented in Table 1.

\section{Experimental Material and Equipment}

3.1. Emotional Induction Materials. The materials used for emotional induction in this study were primarily obtained from the International Affective Picture System (IAPS) and the Chinese Affective Picture System (CAPS). The two databases were designed for the experimental study of emotions, by providing a set of standardized emotional stimuli according to three dimensions: pleasure, arousal, and dominance. Different types of emotion-inducing materials were applied, including audio, visual olfactory, and taste materials. Moreover, participants were also asked to carry out difficult assignment with stress, in order to induce their anxious emotion. Parts of the anxiety induction material are shown in Figure 1.

3.2. Real Driving Experiment. The experimental route consists of a single loop, including two long sides with a length of $1.613 \mathrm{~km}$ (between Beijing Road and Nanjing Road) and two short sides with a length of $0.623 \mathrm{~km}$ (between Qingnian Road and Xincun West Road, as shown in Figure 2). The experimental equipment mainly includes two experimental vehicles, laser radar, laser ranging sensor, high-precision global positioning system, noncontact multifunction speedometer, vehicle recorder, PSYLAB human factor engineering equipment, pedal force manometer, high-definition camera, laptop, and unmanned aerial vehicle (Figure 3). The unmanned aerial vehicle was used for recording the experimental process. Screenshots of real experimental scenes (in Xincun West Road) are illustrated in Figure 4.

3.3. Virtual Driving Experiment. In the virtual driving experiments, a high-fidelity simulator from Japanese manufacturer FORUM 8 was used, which allowed users to construct 3D traffic environment. The Road Builder and UCwin/Road software were used in the driving simulator to build an experimentation platform of the road system with human, vehicle, and road components (Figure 5). The driving simulator was able to collect data on interactions between drivers and vehicles under various traffic conditions. It enables researchers to collect details of useful parameters for drivers' action and vehicle performance, including distance traveled, offset from lane center, speed, acceleration, deceleration, braking, lane-changing, and 
TABLE 1: Statistics of drivers' information.

Number of drivers

Gender

Age

Driving experience

Driving tendency

28

Male; female

Youth $(22-27 \mathrm{y})$

Novice (driving mileage $\leq 10,000 \mathrm{~km}$ )

Experienced (driving mileage $>10,000 \mathrm{~km}$ )
20

Male; female

Middle age $(45-50 y)$

Novice (driving mileage $\leq 10,000 \mathrm{~km}$ )

Experienced (driving mileage $>10,000 \mathrm{~km}$ )

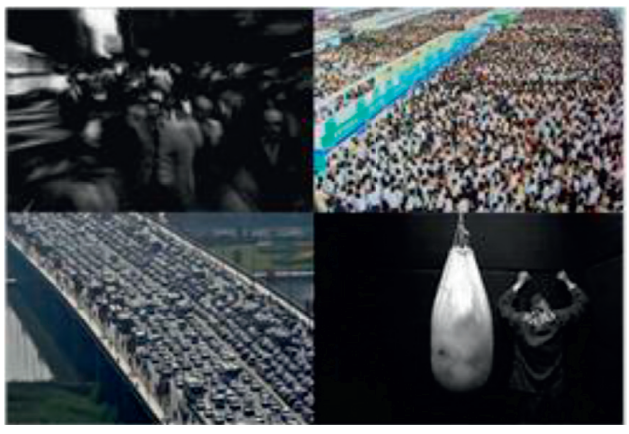

(a)

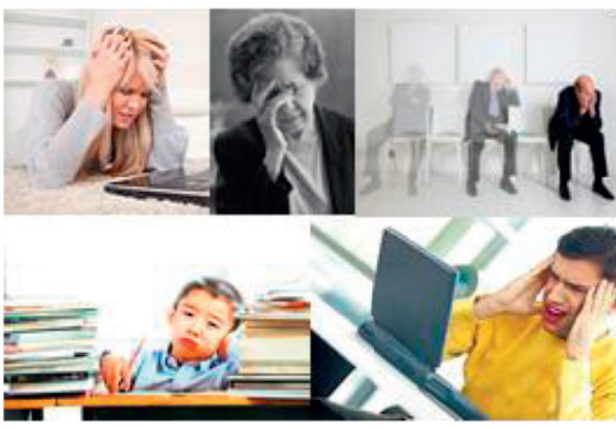

(b)

Figure 1: Parts of the anxiety induction material. (a) Anxiety induction visual materials. (b) Pictures of different people in anxiety.

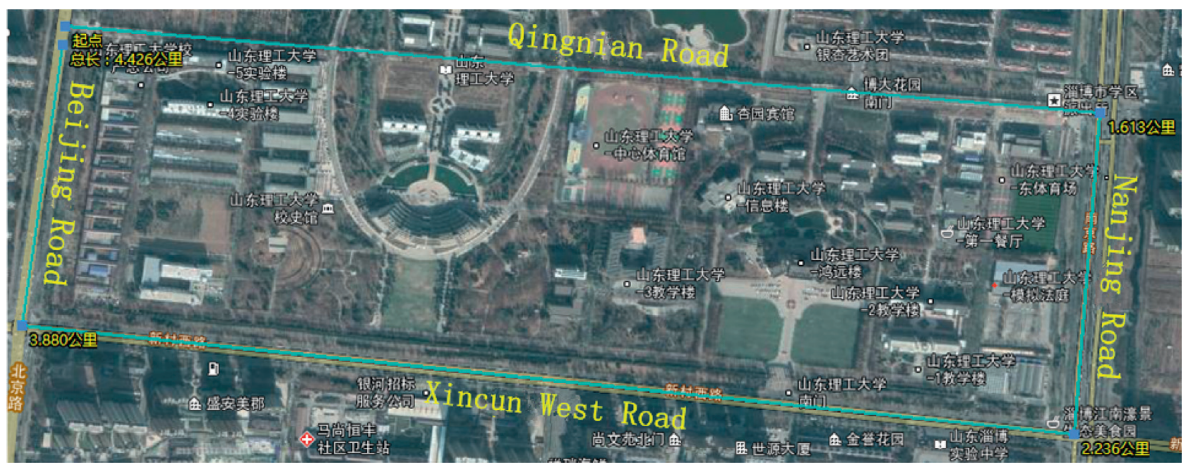

FIGURE 2: Real driving experimental route.

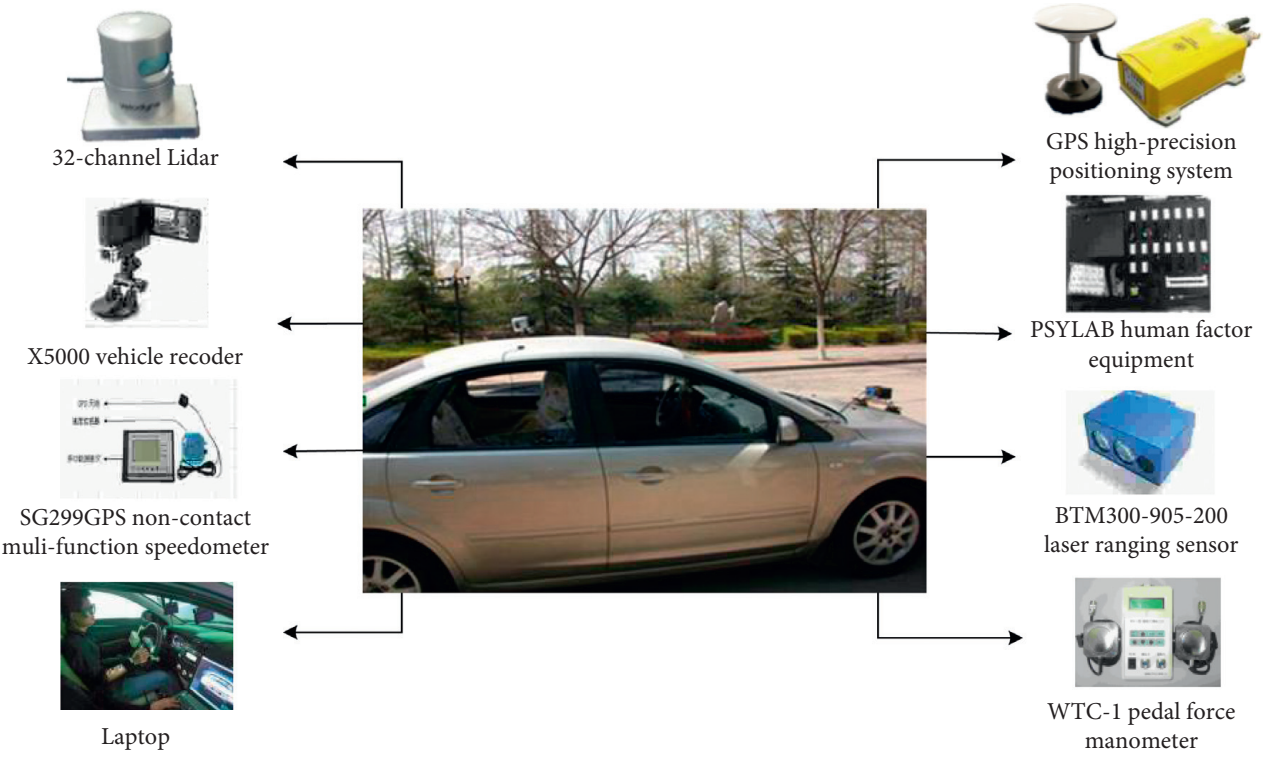

FIgURE 3: Real driving experimental equipment. 


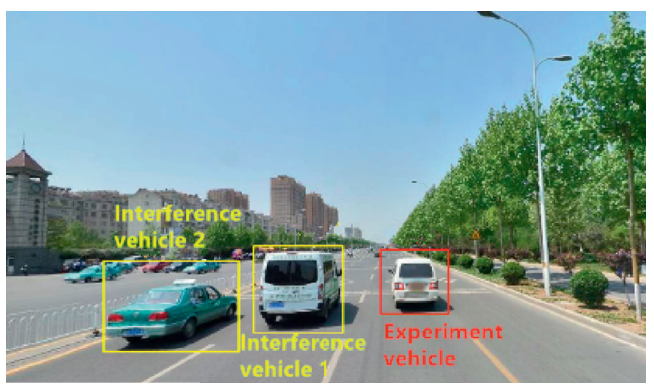

(a)

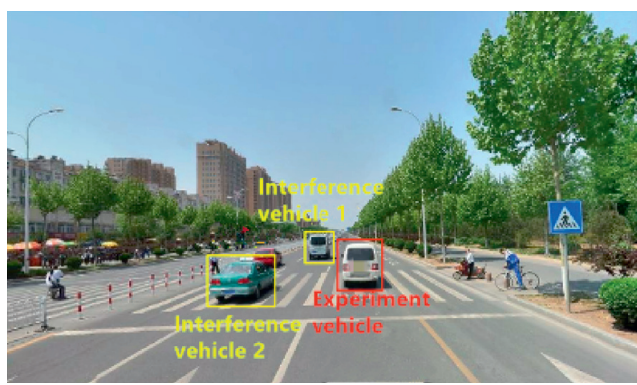

(b)

FIGURE 4: Screenshots of experimental scenes (in Xincun West Road).

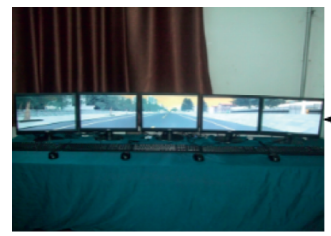

Workstation monitor

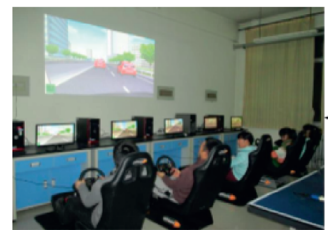

Muti-person muti-machine interactive virtual driving experiment platform

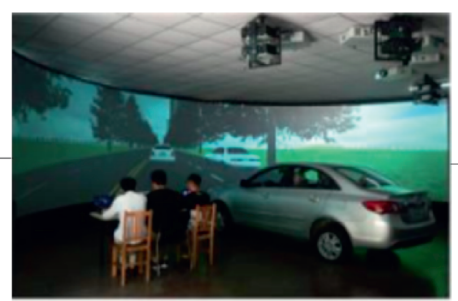

Virtual driving experiment scene

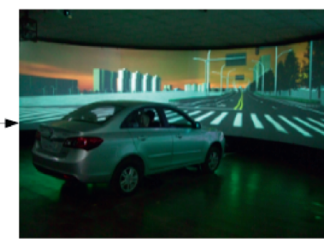

Virtual driving route

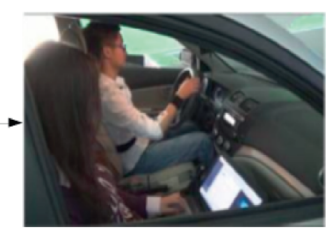

In-vehicle experimenter

FIGURE 5: Virtual driving experimental equipment.

steering angle. The driving simulator can reproduce the road situations similar to reality. Under the virtual environment, the subject can drive just like on the ordinary road, with the same responses as real-life driving. The wearable wireless ECG sensors are shown in Figure 6. The simulation-based experiment route and street view are shown in Figure 7.

3.4. Experimental Process. The real driving experiments in anxiety were carried out during morning peak hours of $7: 00-9$ : 00 and evening peak hours of 17:00-19:00 from Monday to Friday. The experimental process is shown in Figure 8.

3.5. Assessing the Level of the Induced Anxiety. Participant's level of anxiety was detected, based on Beck Anxiety Inventory (BAI), self-perception, facial expression, and behavioral action. The BAI reflects the intensity of physical and cognitive anxiety (Table 2 ). In this study, the emotion-induction experiments end when subjects obtained a score of 26 points or more. During the driving experiment, experimenters irregularly communicate to the subjects to get their emotional states. After the driving experiment, subjects were asked to watch the recorded video to report their emotional experience during driving. For more details about the process of evaluating driver's anxiety level, please refer to our another article by Guo et al. [35].

\section{ECG Signal Data Collection and Preprocessing}

4.1. ECG Signal Data Preprocessing. The raw ECG signals contain motion artifact, power frequency interference, and sensor internal interference noise. The PSYLAB software was used for reducing the noise in the ECG signal, as shown in Figure 9. The definitions of the parameters for denoising preprocess are given in Table 3. The comparison of ECG signal before and after denoising is shown in Figure 10. It was seen that after noise reduction, the noise can be controlled to an acceptable level. For more details about the ECG signal preprocessing, please refer to another article by Wang et al. [36].

4.2. ECG Signal Data Collection. Each subject was involved in driving experiments multiple times. A total of 3849 groups of effective data were obtained, including 983 clusters from the real driving experiments and 2866 clusters from the driving simulators. The variables and symbols in the experiment are given in Table 4. Parts of the experimental data are given in Figure 11 and Table 5. 


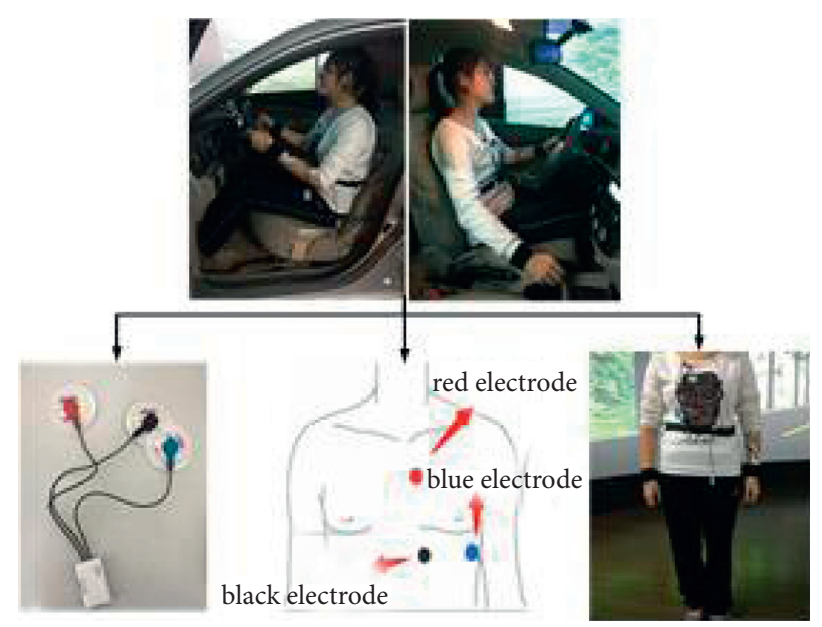

FIgURE 6: The wearable wireless ECG sensors.

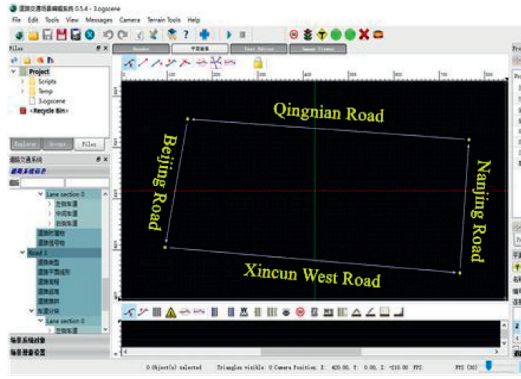

(a)

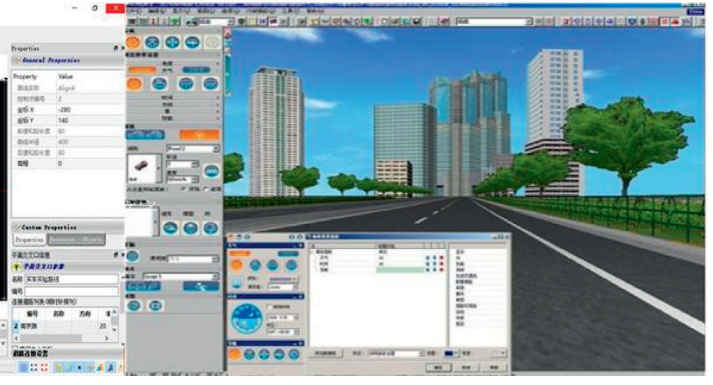

(b)

Figure 7: The simulation-based experiment route and street view.

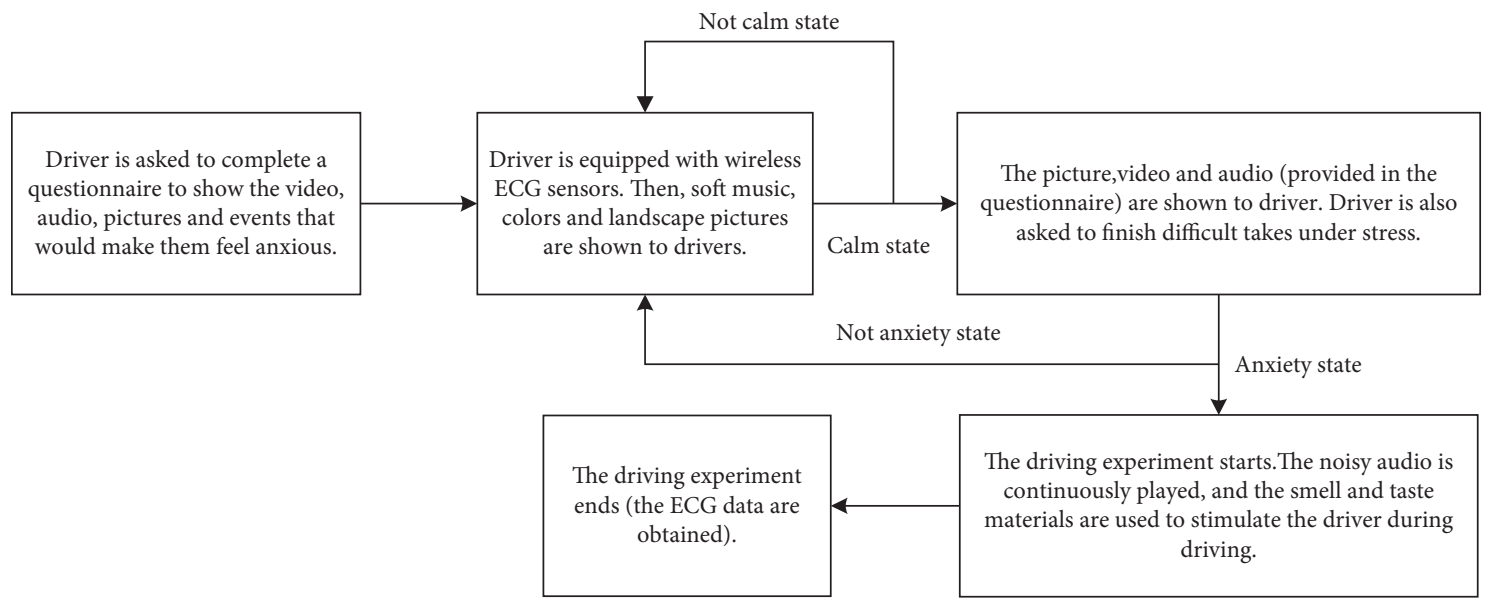

FIGURE 8: The experimental process of real driving in anxiety.

\section{Results and Discussion}

5.1. Driver's ECG Characteristics by Gender. Statistical analysis was performed using SPSS Statistics 23.0 where the confidence interval was set at $95 \%$. The independent $t$-test was used to determine whether there are differences in ECG indicators between female and male drivers, and the results are given in Table 6.
The results show that there are significant differences between male and female drivers in the five ECG indicators: AVHR, AVNN, RWAVE, TWAVE, and $S(p<0.05)$. No significant difference was found between male and female drivers in the other indicators. The results in Figure 12 and Table 6 show that female drivers have higher average heart rate and S-point peaks and lower average heartbeat, $R$ wave peaks, and T-point peaks than male drivers. The results 
TABLE 2: Beck anxiety inventory (BAI).
(1) Body numbness or thorns
(2) Feel feverish
(3) Leg tremble
(4) Cannot relax
(5) Fear of bad things
(6) Feel dizzy
(7) Palpitation
(8) Restless
(9) Frightened
(10) Tension
(11) Suffocation
(12) Hand trembling
(13) Body shake
(14) Afraid of out of control
(15) Difficult breathing
(16) Fear to die
(17) Feel panic
(18) Abdominal discomfort
(19) Faint
(20) Flush
(21) Sweat

Note. The 21 symptoms have four levels of induction. The score of each symptom can be expressed as "1 point-none;" " 2 points-mild, no major annoyance;" " 3 points-moderate, feel uncomfortable but still tolerable;" "4 points-heavy, can only barely endure." The total score of 21 symptoms is $15-25$ points for mild anxiety, 26-35 points for moderate anxiety, and more than 36 points for severe anxiety.

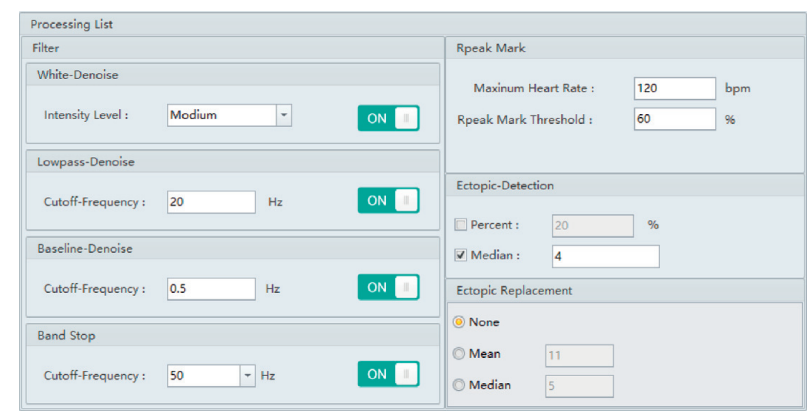

FIGURE 9: Denoising preprocess interface for original ECG signal.

TABLE 3: The definitions of parameters for denoising preprocess.

\begin{tabular}{lcc}
\hline White-denoise & Baseline-denoise & Lowpass-denoise \\
$\begin{array}{l}\text { Remove white noise } \\
\text { from ECG signals }\end{array}$ & $\begin{array}{c}\text { High frequency signal is retained and low } \\
\text { frequency signal is cut off }\end{array}$ & $\begin{array}{c}\text { Low frequency signal is retained and high Remo } \\
\text { frequency signal is cut off }\end{array}$ \\
\hline
\end{tabular}

FIGURE 10: Comparison of ECG signal before and after denoising.

indicate that compared to male drivers, female drivers tend to have a faster heart rate, a shorter heartbeat interval, and a more obvious manifestation of myocardial ischemia in anxiety while driving.
Under moderate and high levels of anxiety, female drivers are more likely to experience dizziness, slow response, and fidgeting due to rapid heartbeat and poor blood flow to the heart. Moreover, females are more likely to have 
TABLE 4: Variables and symbols in the experiment.

\begin{tabular}{lc}
\hline Variable & Symbol \\
\hline Gender & G \\
Age (year) & D \\
Driving experience (ten thousand kilometers) & T \\
Driving tendency & RWAVE \\
Emotion & TWAVE \\
R wave average peak $(u V)$ & Q \\
T wave average peak $(u V)$ & S \\
Q wave average peak absolute value $(u V)$ & AVHR \\
S wave average peak absolute value $(u V)$ & AVNN \\
Average heart rate $(b p m)$ & SDNN \\
Atrioventricular interval (ms) & PNN \\
Standard deviation of NN intervals for period of interest (ms) & RMSSD \\
Percent of NN intervals $>50$ ms $(\%)$ & UVLF/VLF \\
Root mean square of successive (ms) & LF/HF \\
Ratio of ultralow frequency band to very low frequency band & TP \\
Ratio of low frequency band to high frequency band & \\
Total power $\left(m s^{2}\right)$ &
\end{tabular}

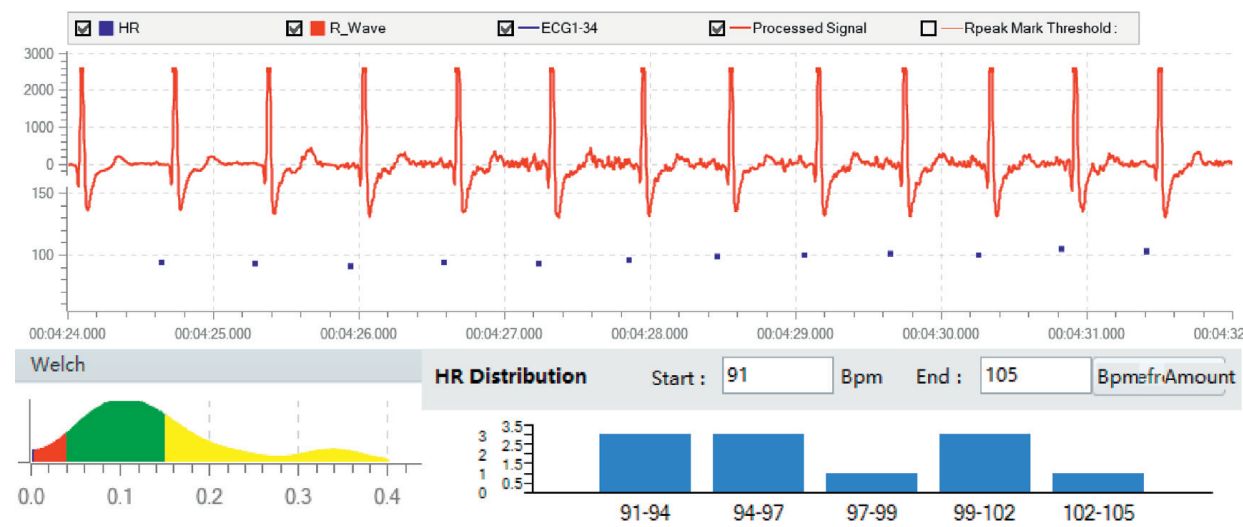

(a)

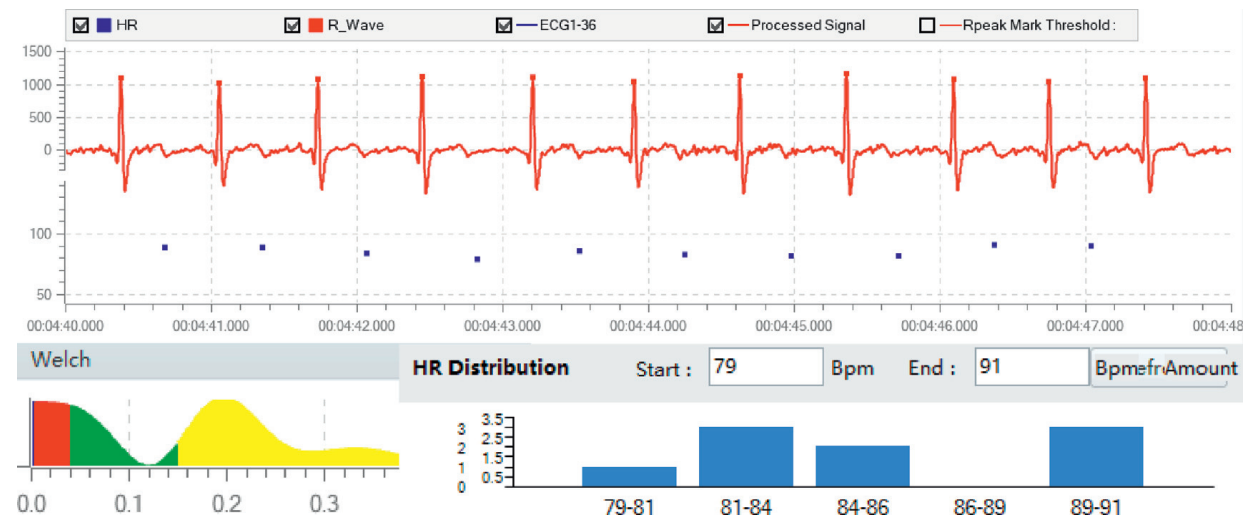

(b)

FIGURE 11: Distribution of driver's ECG data distribution in anxiety. (a) Driver's heart rate and frequency distribution (male * $27 \mathrm{y}$ * novice * middle type). (b) Driver's heart rate and frequency distribution (female * $27 \mathrm{y}$ * experienced * introversion).

chest distress, shortness of breath, as well as discomfort in the arms, neck, and shoulders as with myocardial ischemia. These symptoms might contribute to distraction, difficulty keeping the eyes from focusing, and slow reaction during driving. The results in Figure 12 suggest that these gender differences in the symptoms may be more pronounced in middle-aged drivers than in young ones, especially for novice and introverted drivers. 
TABLE 5: Statistics of driver's ECG characteristic data.

\begin{tabular}{|c|c|c|c|c|c|c|c|c|c|}
\hline No. & $\mathrm{G}$ & $\mathrm{D}$ & $\mathrm{Em}$ & AVHR & AVNN & SDNN & PNN50 & RMSSD & RWAVE \\
\hline \multirow{3}{*}{1} & Male & 0.4 & & 95 & 632.60 & 129.36 & 15.56 & 158.32 & 2559.27 \\
\hline & A & $\mathrm{T}$ & Anxiety & TWAVE & Q & S & UVLF/VLF & $\mathrm{LF} / \mathrm{HF}$ & $\mathrm{TP}$ \\
\hline & 22 & Extraversion & & 392.78 & -431.67 & -1554.49 & 0.07 & 1.07 & 2641.22 \\
\hline \multirow[t]{2}{*}{ No. } & $\mathrm{G}$ & $\mathrm{D}$ & Em & AVHR & AVNN & SDNN & PNN50 & RMSSD & RWAVE \\
\hline & Male & 0.50 & & 88 & 680.96 & 57.79 & 11.90 & 32.10 & 2559.17 \\
\hline \multirow[t]{2}{*}{2} & A & $\mathrm{T}$ & Anxiety & TWAVE & Q & S & UVLF/VLF & $\mathrm{LF} / \mathrm{HF}$ & TP \\
\hline & 27 & Middle type & & 363.74 & -469.37 & -1513.37 & 0.13 & 9.56 & 1123.26 \\
\hline \multirow[t]{2}{*}{ No. } & $\mathrm{G}$ & $\mathrm{D}$ & Em & AVHR & AVNN & SDNN & PNN50 & RMSSD & RWAVE \\
\hline & Female & 0.30 & & 102 & 586.65 & 45.39 & 5.70 & 12.91 & 2234.62 \\
\hline \multirow[t]{3}{*}{3} & A & $\mathrm{T}$ & Anxiety & TWAVE & Q & S & UVLF/VLF & $\mathrm{LF} / \mathrm{HF}$ & $\mathrm{TP}$ \\
\hline & 24 & Extraversion & & 360.99 & -399.78 & -1260.28 & 0 & 12.89 & 749.11 \\
\hline & $\ldots$ & & & $\ldots$ & & $\ldots$ & & $\ldots$ & \\
\hline \multirow[t]{2}{*}{ No. } & $\mathrm{G}$ & $\mathrm{D}$ & Em & AVHR & AVNN & SDNN & PNN50 & RMSSD & RWAVE \\
\hline & Female & 1.30 & & 84 & 713.37 & 31.37 & 2.50 & 27.41 & 1171.33 \\
\hline \multirow[t]{2}{*}{$n-1$} & A & $\mathrm{T}$ & Anxiety & TWAVE & Q & S & UVLF/VLF & $\mathrm{LF} / \mathrm{HF}$ & $\mathrm{TP}$ \\
\hline & 50 & Introversion & & 110.52 & -209.44 & -685.18 & 0.01 & 7.18 & 565.47 \\
\hline \multirow[t]{2}{*}{ No. } & $\mathrm{G}$ & $\mathrm{D}$ & Em & AVHR & AVNN & SDNN & PNN50 & RMSSD & RWAVE \\
\hline & Male & 3.80 & & 81 & 743.24 & 161.12 & 47.37 & 232.41 & 1920.80 \\
\hline \multirow[t]{2}{*}{$\mathrm{n}$} & A & $\mathrm{T}$ & Anxiety & TWAVE & Q & S & UVLF/VLF & $\mathrm{LF} / \mathrm{HF}$ & $\mathrm{TP}$ \\
\hline & 50 & Introversion & & 255.69 & -235.46 & -880.28 & 0.06 & 1.73 & 5497.79 \\
\hline
\end{tabular}

TABLE 6: Independent $t$-test results of ECG characteristics for male and female drivers in anxiety.

\begin{tabular}{|c|c|c|c|c|c|c|c|c|}
\hline & & \multirow[t]{2}{*}{$t$} & \multirow[t]{2}{*}{ df } & \multirow[t]{2}{*}{ Significance (2-tailed) } & \multirow[t]{2}{*}{ Mean difference } & \multirow[t]{2}{*}{ Standard error difference } & \multicolumn{2}{|c|}{$\begin{array}{c}95 \% \text { confidence } \\
\text { interval of the } \\
\text { difference }\end{array}$} \\
\hline & & & & & & & Lower & Upper \\
\hline AVHR & M-F & -4.196 & 8 & 0.003* & -2.778 & 0.662 & -4.304 & -1.251 \\
\hline AVNN & M-F & 5.218 & 8 & $0.001^{*}$ & 22.135 & 4.242 & 12.353 & 31.918 \\
\hline SDNN & M-F & 0.9 & 8 & 0.394 & 17.703 & 19.671 & -27.658 & 63.064 \\
\hline $\mathrm{PNN}_{50}$ & M-F & 2.291 & 8 & 0.051 & 10.841 & 4.732 & -0.718 & 21.754 \\
\hline RMSSD & M-F & 1.713 & 8 & 0.125 & 53.675 & 31.333 & -18.579 & 125.93 \\
\hline RWAVE & M-F & 4.197 & 8 & $0.003^{*}$ & 341.24 & 81.302 & 153.761 & 528.726 \\
\hline TWAVE & M-F & 9.601 & 8 & $0.000^{*}$ & 109.6 & 11.416 & 83.281 & 135.932 \\
\hline $\mathrm{Q}$ & M-F & -1.698 & 8 & 0.128 & -28.3 & 16.672 & -66.753 & 10.137 \\
\hline S & $\mathrm{M}-\mathrm{F}$ & -15.118 & 8 & $0.000^{*}$ & -219.3 & 14.509 & -252.808 & -185.892 \\
\hline UVLF/VLF & M-F & -0.364 & 8 & 0.725 & -0.009 & 0.024 & -0.065 & 0.047 \\
\hline $\mathrm{LF} / \mathrm{HF}$ & $\mathrm{M}-\mathrm{F}$ & 0.034 & 8 & 0.973 & 0.104 & 3.035 & -6.894 & 7.104 \\
\hline $\mathrm{TP}$ & M-F & 0.88 & 8 & 0.404 & 298.59 & 339.158 & -483.501 & 1080.699 \\
\hline
\end{tabular}

Note. The significance level is 0.05 . M-F, male-female.

5.2. Driver's ECG Characteristics by Age. The independent $t$-test results (in Table 7) show that there are significant differences between middle-aged and young drivers in the seven ECG indicators AVHR, AVNN, RWAVE, TWAVE, $\mathrm{Q}, \mathrm{S}$, and UVLF/VLF $(p<0.05)$. There is no significant difference between middle-aged and young drivers in the other indicators. The results in Figure 13 and Table 7 show that young drivers have higher average heart rate, $R$ wave peaks, and T-point peaks than middle-aged drivers. Furthermore, young drivers have lower average heartbeat interval, Q-point peaks, S-point peaks, and the ratio of ultralow frequency band to very low frequency band than middle-aged drivers. The results indicate that compared to middle-aged drivers, young drivers tend to have a faster heart rate, a shorter heartbeat interval, a higher pulse pressure, a greater sympathetic nerve activity, and a higher rate of left ventricular hypertrophy and hyperkalemia in anxiety.

In moderate and severe cases, young drivers are more likely to feel dizziness and chest distress due to rapid heartbeat and poor blood flow to the heart. Young drivers are also more likely to suffer from muscle stiffness as with hyperkalemia. These symptoms might contribute to slow response and maintain head-down position (vision at low location). As a result, young drivers might pay less attention on traffic environment of the sides and the straight ahead in the far while driving. These age differences in the symptoms are more obvious in female drivers than in male ones. 


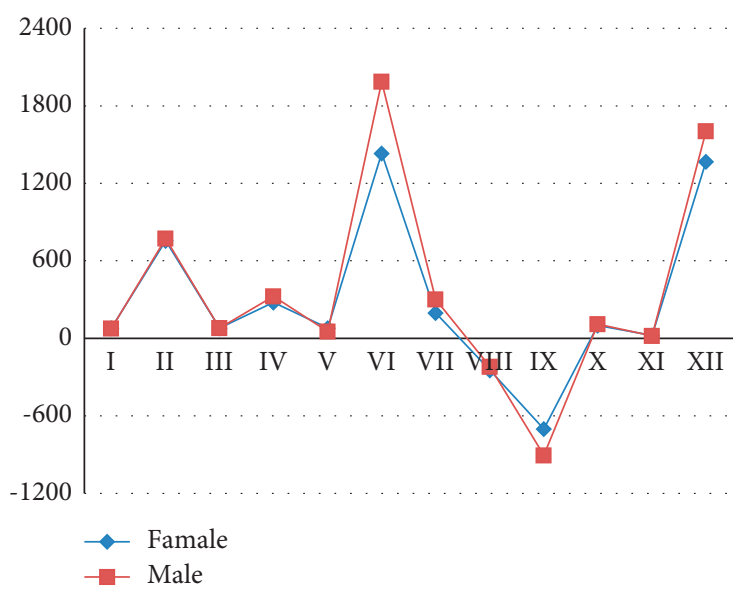

(a)

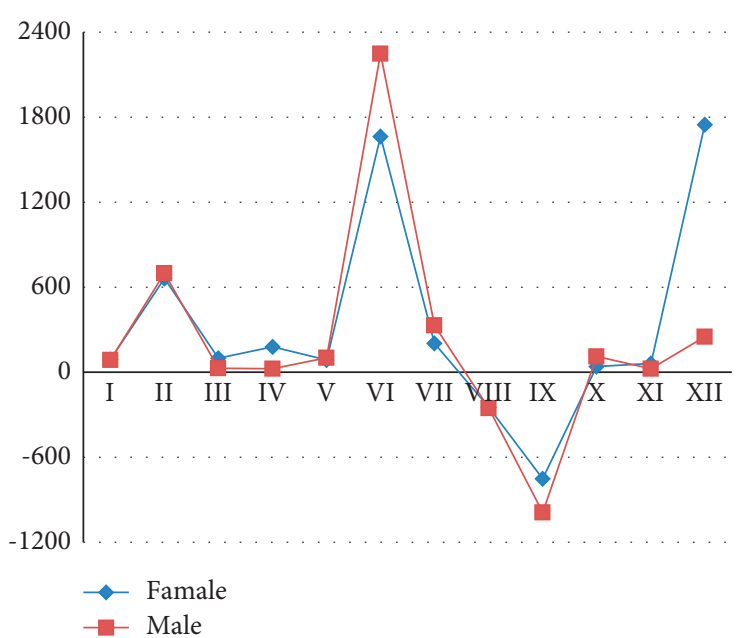

(c)

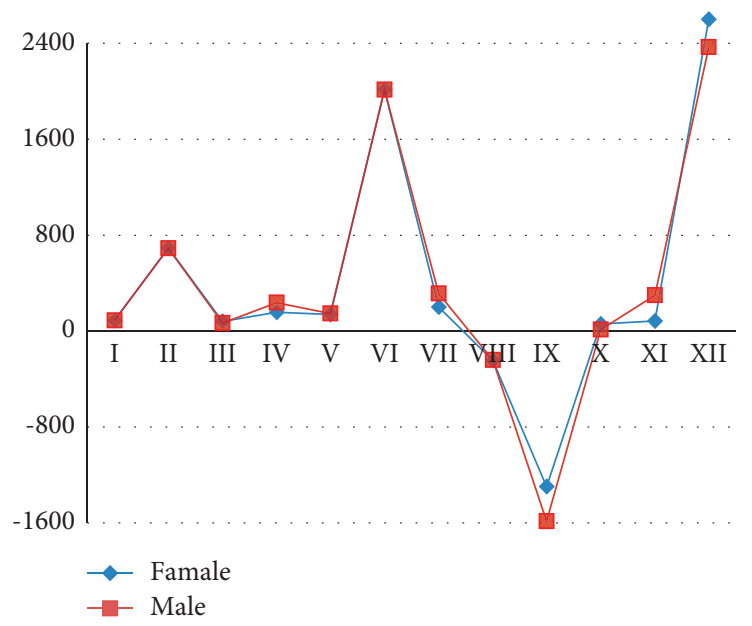

(e)

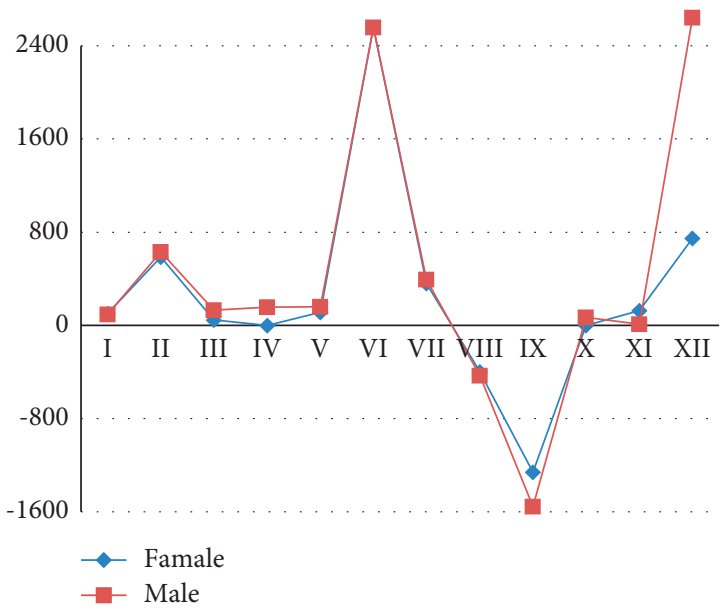

(b)

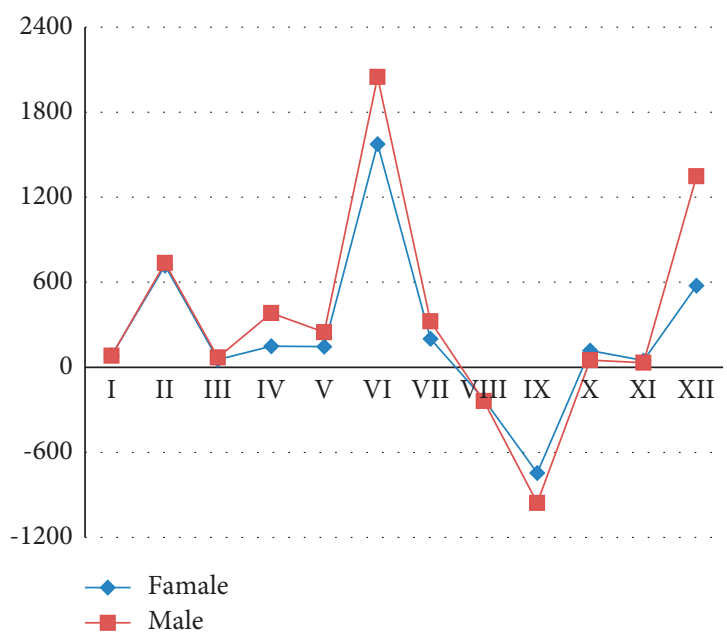

(d)

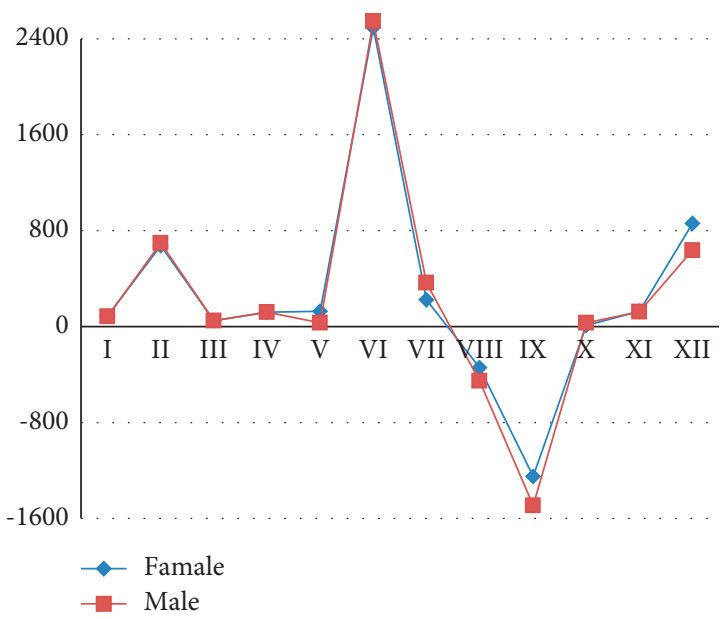

(f)

Figure 12: Male and female drivers' ECG characteristics in anxiety. (a) 45-50 years old * novice * extraversion. (b) 45-50 years old * novice ${ }^{*}$ middle type. (c) 45-50 years old * novice * introversion (d) 22-27 years old * novice * extraversion. (e) 22-27 years old * novice * middle type. (f) 22-27 years old * novice * introversion (I, AVHR; II, AVNN; III, SDNN; IV, PNN 50 ; V, RMSSD; VI, RWAVE; VII, TWAVE; VIII, Q; IX, S; X, UVLF/VLF*1000; XI, LF/HF*100; XII, TP). 
TABLE 7: Independent $t$-test results of ECG characteristics for young and middle-aged drivers in anxiety.

\begin{tabular}{|c|c|c|c|c|c|c|c|c|}
\hline & & \multirow[t]{2}{*}{$t$} & \multirow[t]{2}{*}{ df } & \multirow[t]{2}{*}{ Significane (2-tailed) } & \multirow[t]{2}{*}{ Mean difference } & \multirow[t]{2}{*}{ Standard error difference } & \multicolumn{2}{|c|}{$\begin{array}{l}95 \% \text { confidence } \\
\text { interval of the } \\
\text { difference }\end{array}$} \\
\hline & & & & & & & Lower & Upper \\
\hline AVHR & M-Y & -5.358 & 5 & $\mathbf{0 . 0 0 3}^{*}$ & -8.5 & 1.586 & -12.578 & -4.422 \\
\hline AVNN & M-Y & 5.604 & 5 & $0.002^{*}$ & 69.225 & 12.352 & 37.473 & 100.977 \\
\hline SDNN & M-Y & -0.461 & 5 & 0.664 & -13.6 & 29.487 & -89.403 & 62.193 \\
\hline $\mathrm{PNN}_{50}$ & M-Y & 2.082 & 5 & 0.092 & 10.488 & 5.038 & -2.462 & 23.439 \\
\hline RMSSD & M-Y & -0.553 & 5 & 0.604 & -10.84 & 19.621 & -61.286 & 39.589 \\
\hline RWAVE & M-Y & -5.907 & 5 & $0.002^{*}$ & -715.7 & 121.187 & -1027.313 & -404.273 \\
\hline TWAVE & M-Y & -3.812 & 5 & $0.012^{*}$ & -71.08 & 18.646 & -119.01 & -23.15 \\
\hline Q & M-Y & 7.604 & 5 & $0.001^{*}$ & 171.05 & 22.495 & 113.231 & 228.882 \\
\hline S & M-Y & 41.944 & 5 & $0.000^{*}$ & 545.87 & 13.015 & 512.423 & 579.333 \\
\hline UVLF/VLF & M-Y & 6.29 & 5 & $0.001^{*}$ & 0.062 & 0.01 & 0.036 & 0.087 \\
\hline $\mathrm{LF} / \mathrm{HF}$ & M-Y & -1.651 & 5 & 0.16 & -3.937 & 2.384 & -10.064 & 2.191 \\
\hline $\mathrm{TP}$ & M-Y & -0.645 & 5 & 0.547 & -367.1 & 568.955 & -1829.7 & 1095.386 \\
\hline
\end{tabular}

Note. The significance level is 0.05 . M-Y, middle aged-young.

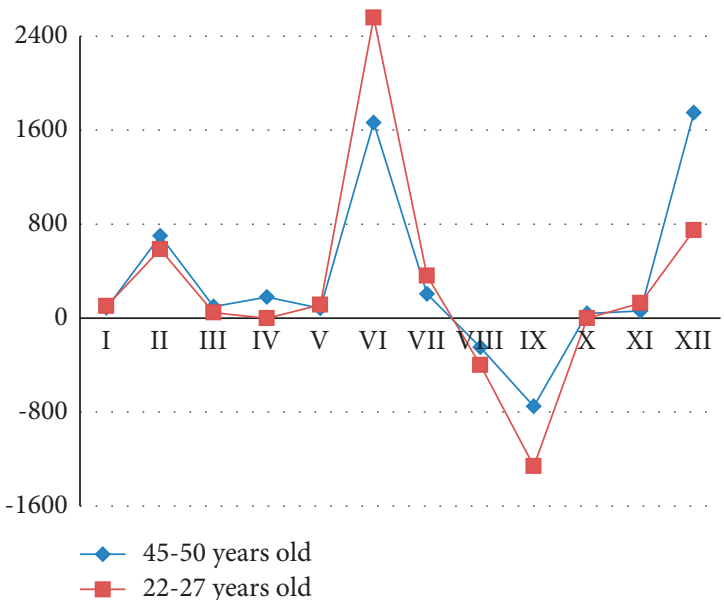

(a)

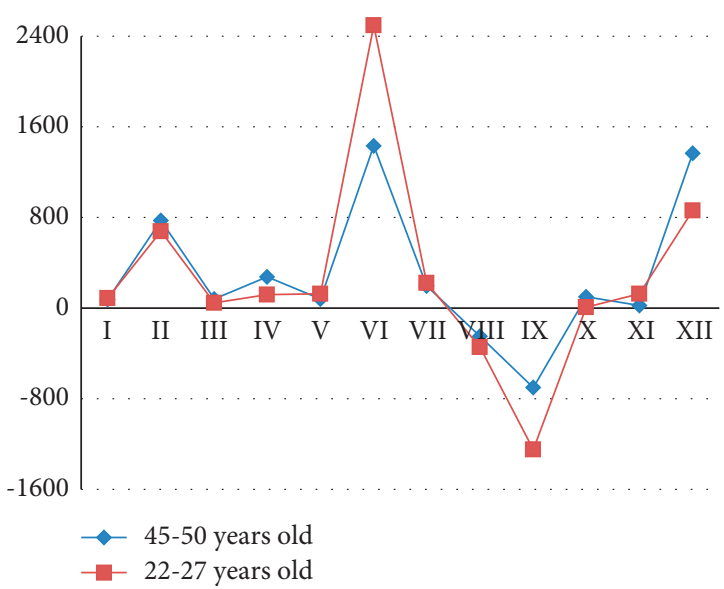

(c)

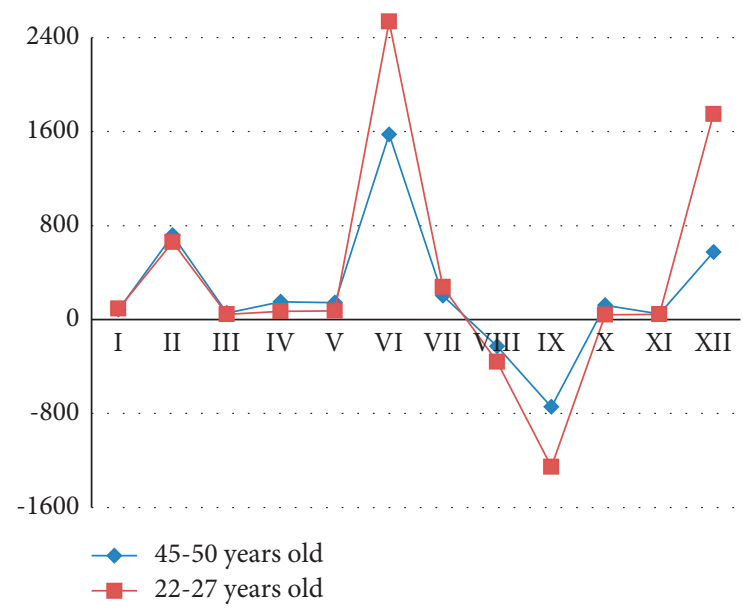

(b)

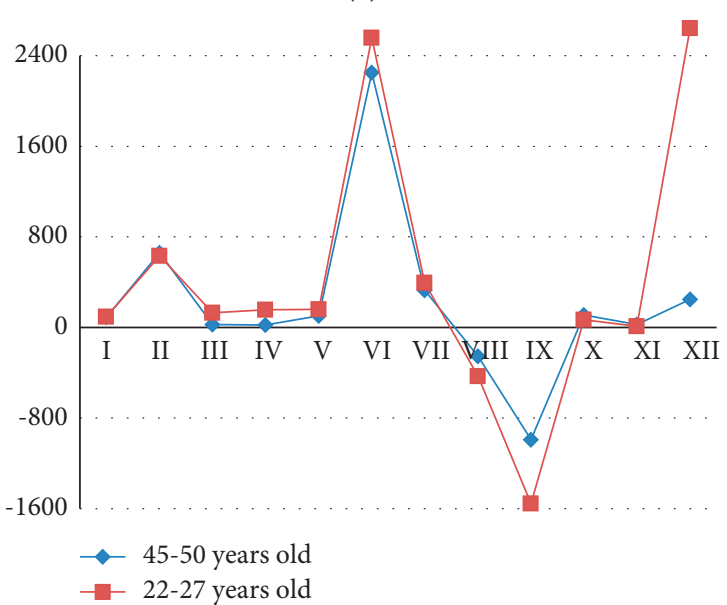

(d)

Figure 13: Continued. 


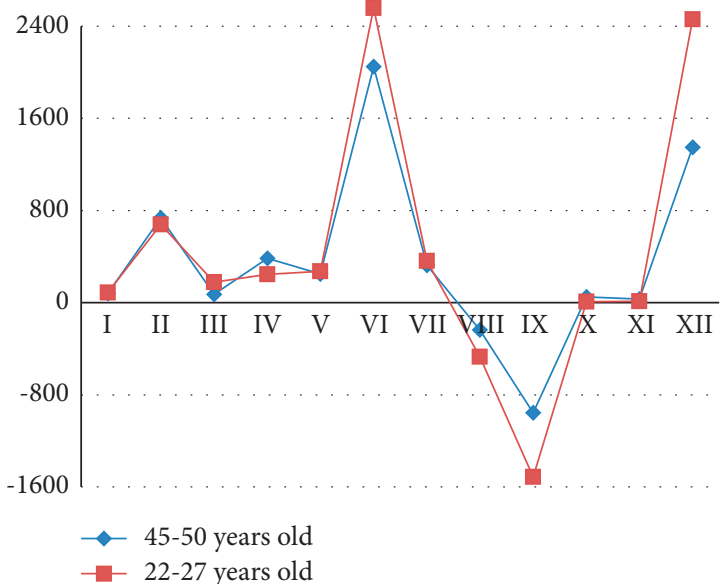

(e)

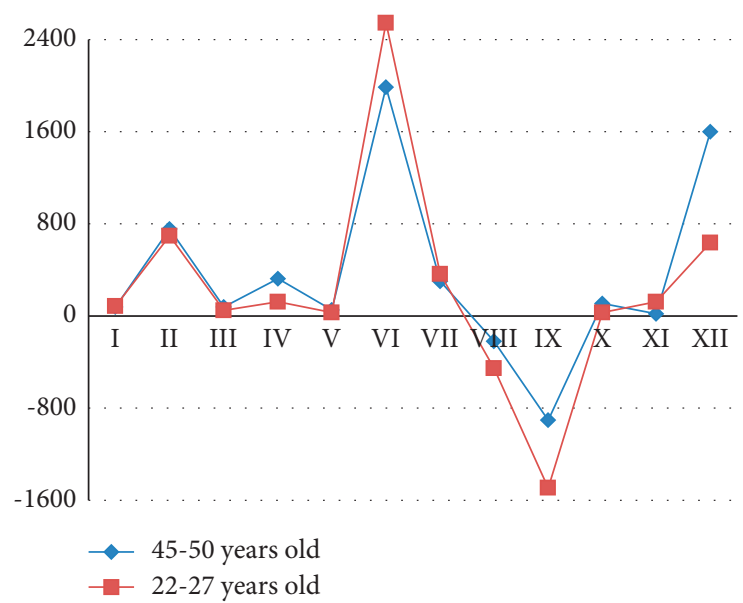

(f)

FiguRe 13: Young and middle age drivers' ECG characteristics in anxiety. (a) Female * novice * extraversion. (b) Female * novice * middle type. (c) Female * novice * introversion. (d) Male * novice * extraversion. (e) Male * novice * middle type. (f) Male * novice * introversion (I, AVHR; II, AVNN; III, SDNN; IV, PNN 50 ; V, RMSSD; VI, RWAVE; VII, TWAVE; VIII, Q; IX, S; X, UVLF/VLF*1000; XI, LF/HF*100; XII, TP).

TABLE 8: Independent $t$-test results of ECG characteristics for novice and experienced drivers in anxiety.

\begin{tabular}{|c|c|c|c|c|c|c|c|c|}
\hline & & \multirow[t]{2}{*}{$t$} & \multirow[t]{2}{*}{$\mathrm{df}$} & \multirow[t]{2}{*}{ Significance (2-tailed) } & \multirow[t]{2}{*}{ Mean difference } & \multirow[t]{2}{*}{ Standard error difference } & \multicolumn{2}{|c|}{$\begin{array}{l}\text { 95\% confidence } \\
\text { interval of the } \\
\text { difference }\end{array}$} \\
\hline & & & & & & & Lower & Upper \\
\hline AVHR & $\mathrm{N}-\mathrm{E}$ & 2.928 & 5 & $0.033^{*}$ & 2.000 & 0.683 & 0.244 & 3.756 \\
\hline AVNN & $\mathrm{N}-\mathrm{E}$ & -2.535 & 5 & $0.042^{*}$ & -18.510 & 7.304 & -37.289 & 0.259 \\
\hline SDNN & $\mathrm{N}-\mathrm{E}$ & 0.821 & 5 & 0.449 & 7.620 & 9.28 & -16.234 & 31.474 \\
\hline $\mathrm{PNN}_{50}$ & $\mathrm{~N}-\mathrm{E}$ & -0.221 & 5 & 0.834 & -1.010 & 4.577 & -12.775 & 10.755 \\
\hline RMSSD & $\mathrm{N}-\mathrm{E}$ & -0.777 & 5 & 0.472 & -19.730 & 25.394 & -85.011 & 45.545 \\
\hline RWAVE & $\mathrm{N}-\mathrm{E}$ & 3.414 & 5 & $0.019^{*}$ & 98.015 & 28.706 & 24.223 & 171.807 \\
\hline TWAVE & $\mathrm{N}-\mathrm{E}$ & 2.323 & 5 & 0.068 & 29.490 & 12.693 & -3.139 & 62.119 \\
\hline $\mathrm{Q}$ & N-E & -1.011 & 5 & 0.358 & -7.527 & 7.446 & -26.667 & 11.613 \\
\hline S & $\mathrm{N}-\mathrm{E}$ & -2.814 & 5 & $0.037^{*}$ & -34.020 & 12.093 & -65.113 & -2.941 \\
\hline UVLF/VLF & N-E & 0.989 & 5 & 0.368 & 0.030 & 0.03 & -0.048 & 0.108 \\
\hline $\mathrm{LF} / \mathrm{HF}$ & N-E & -1.510 & 5 & 0.192 & -6.453 & 4.275 & -17.443 & 4.536 \\
\hline $\mathrm{TP}$ & $\mathrm{N}-\mathrm{E}$ & -1.010 & 5 & 0.359 & -428.700 & 424.638 & -1520.36 & 662.77 \\
\hline
\end{tabular}

Note. The significance level is 0.05 . N-E, novice-experienced.

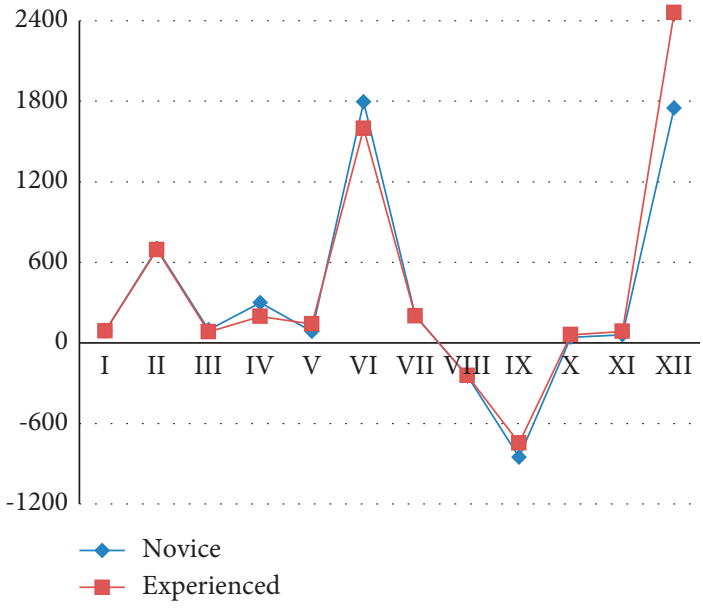

(a)

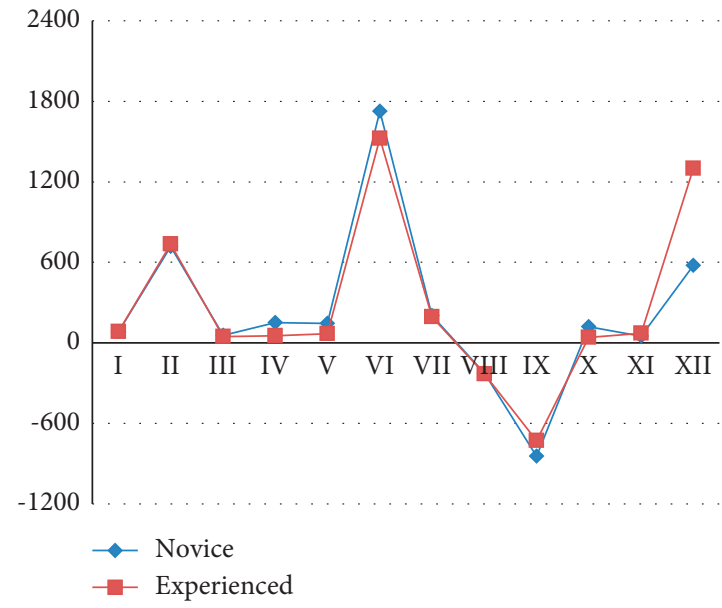

(b)

FIgure 14: Continued. 


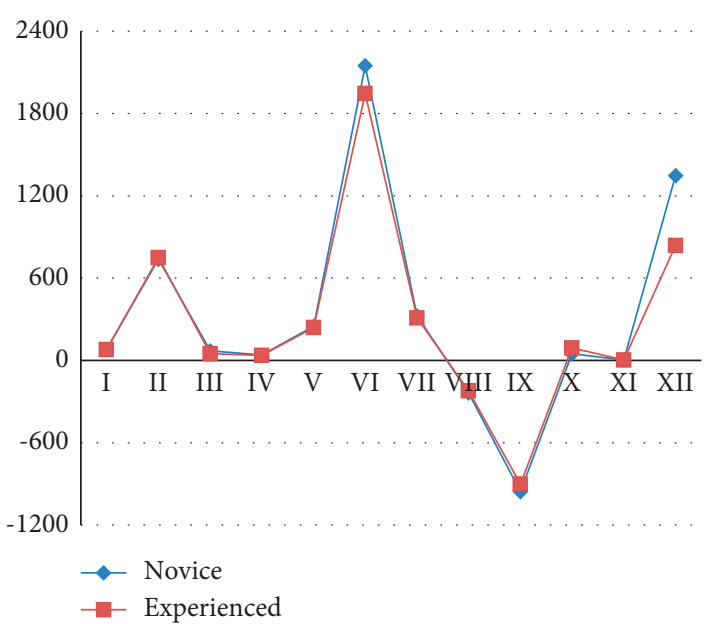

(c)

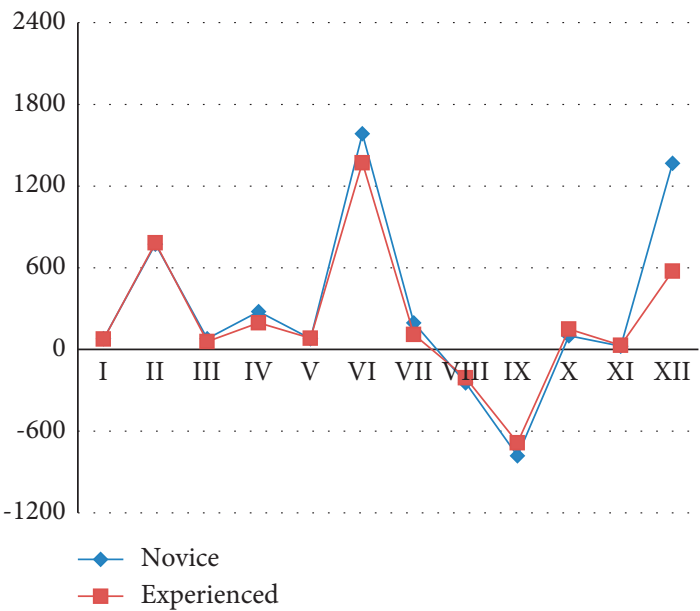

(e)

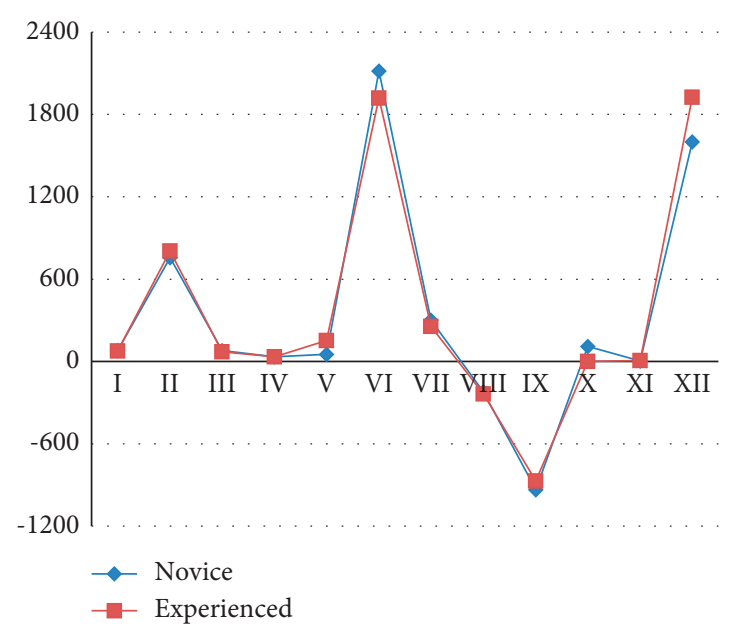

(d)

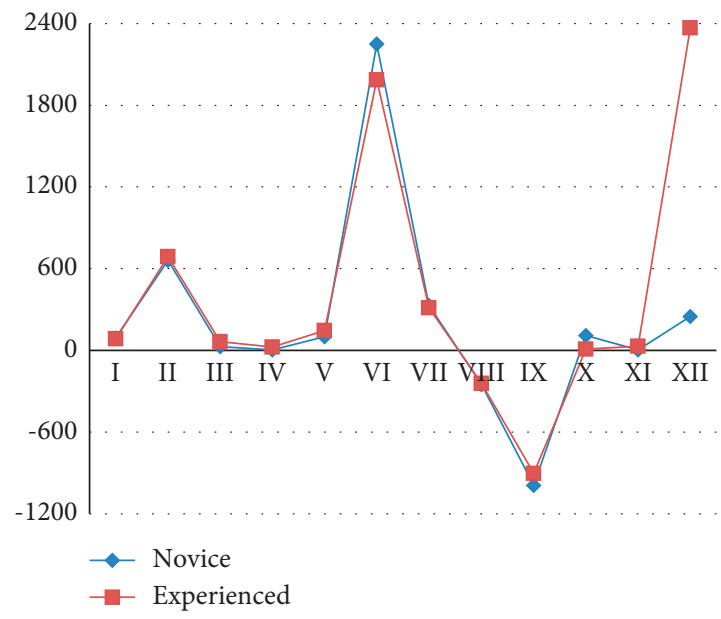

(f)

Figure 14: Novice and experienced drivers' ECG characteristics in anxiety. (a) Female * 45-50 years old * extraversion. (b) Female * 45-50 years old * middle type. (c) Female * 45-50 years old * introversion. (d) Male * 45-50 years old * extraversion. (e) Male * 45-50 years old * middle type. (f) Male * 45-50 years old * introversion (I, AVHR; II, AVNN; III, SDNN; IV, PNN 50 ; V, RMSSD; VI, RWAVE; VII, TWAVE; VIII, Q; IX, S; X, UVLF/VLF*1000; XI, LF/HF*100; XII, TP).

Moreover, it should be noted that high levels of sympathetic nerve activity, left ventricular hypertrophy, and pulse pressure occur rarely in young individuals during driving.

\subsection{Driver's ECG Characteristics by Driving Experiences.} The independent $t$-test results (Table 8) show that there are significant differences between novice and experienced drivers in the four ECG indicators, AVHR, AVNN, RWAVE, and $S(p<0.05)$. No significant difference was found between novice and experienced drivers in the other indicators. The results in Figure 14 and Table 8 show that novice drivers have higher average heart rate and $R$-wave peaks and lower average heartbeat interval and S-point peaks than experienced drivers. The results indicate that compared to experienced drivers, novice drivers tend to have a faster heart rate, a shorter heartbeat interval, and an aberrant ventricular conduction in anxiety.

In moderate and severe cases, novices are more likely to experience sweating and nervous intense due to rapid heartbeat. Novices are also more likely to suffer from shortness of breath as with aberrant ventricular conduction. These symptoms might cause long fixation duration and behavioral inflexibility to react to sudden events during driving.

\section{Conclusion}

This study identified the differences of ECG characteristics for different types of drivers under anxiety. The real and virtual driving experiments were designed and conducted to collect driver ECG signal data. The data were analyzed by gender, age, and driving experience. The main findings are demonstrated as follows.

(1) Compared to male drivers, female drivers tend to have a faster heart rate, a shorter heartbeat interval, and a more obvious manifestation of myocardial ischemia in anxiety. Under moderate and high levels of anxiety, female drivers are more likely to 
experience dizziness, slow response, and fidgeting due to rapid heartbeat. Moreover, females are more likely to have chest distress, shortness of breath, as well as discomfort in the arms, neck, and shoulders as with myocardial ischemia.

(2) Compared to middle-aged drivers, young drivers tend to have a faster heart rate, a shorter heartbeat interval, a higher pulse pressure, a greater sympathetic nerve activity, and a higher rate of left ventricular hypertrophy and hyperkalemia in anxiety. In moderate and severe cases, young drivers are more likely to feel dizziness and chest distress due to rapid heartbeat. Young drivers are also more likely to suffer from muscle stiffness as with hyperkalemia.

(3) Compared to experienced drivers, novice drivers tend to have a faster heart rate, a shorter heartbeat interval, and an aberrant ventricular conduction in anxiety. In moderate and severe cases, novices are more likely to experience sweating and nervous intense due to rapid heartbeat. Novices are also more likely to suffer from shortness of breath as with aberrant ventricular conduction.

Our findings of this study suggest that ECG signals closely reflect driver's emotional state and can be used to detect driver's physical state. The findings also contribute to the development of the intelligent and personalized driver warning system, which could improve road traffic safety. Further studies are required to gather additional ECG data for different types of drivers and determine the factors affecting the ECG characteristics in emotional states.

\section{Data Availability}

The data used to support the findings of this study are available from the corresponding author upon request.

\section{Conflicts of Interest}

The authors declare that there are no conflicts of interest.

\section{Acknowledgments}

This study was supported by the Joint Laboratory for Internet of Vehicles, Ministry of Education-China Mobile Communications Corporation (ICV-KF2018-03), Qingdao Top Talent Program of Entrepreneurship and Innovation (19-3-2-8-zhc), the National Natural Science Foundation of China (71901134, 61074140, and 61573009), and the National Key R\&D Program of China (2017YFC0803802).

\section{References}

[1] X. Y. Wang, J. L. Zhang, and X. G. Ban, Vehicle Driving Tendency Identification Based on Collaborative Simulation of Dynamic Human-Vehicle Environment, Science Press, Beijing, China, 2013.

[2] H. F. Jia, Y. X. Si, and M. Tang, "Study on driver information processing mode based on cognitive psychology," China Safety Science Journal, vol. 16, no. 1, pp. 22-25, 2006.
[3] L. X. Yan, C. Z. Wu, and S. Gao, "Study on the relationship between driver's individual factors and driving anger," Journal of Transport Information and Safety, vol. 31, pp. 119-124, 2013.

[4] M. Schmidt-Daffy, "Velocity versus safety: impact of goal conflict and task difficulty on drivers' behaviour, feelings of anxiety, and electrodermal responses," Transportation Research Part F: Traffic Psychology and Behaviour, vol. 15, no. 3, pp. 319-332, 2012.

[5] J. Naveteur, S. Cœugnet, C. Charron, L. Dorn, and F. Anceaux, "Impatience and time pressure: subjective reactions of drivers in situations forcing them to stop their car in the road," Transportation Research Part F: Traffic Psychology and Behaviour, vol. 18, no. 22, pp. 58-71, 2013.

[6] B. Geethanjali, K. Adalarasu, M. Jagannath, and N. P. Guhan Seshadri, "Music induced emotion using wavelet packet decomposition-An EEG study," Biomedical Signal Processing and Control, vol. 45, pp. 115-128, 2018.

[7] X. Zhang, B. Zuo, K. Erskine, and T. Hu, "Feeling light or dark? emotions affect perception of brightness," Journal of Environmental Psychology, vol. 47, pp. 107-111, 2016.

[8] L. Wang, Y. Bie, and S. Li, "The impact of roadside landscape colors on driver's mean heart rate considering driving time," Transportation Research Part F: Traffic Psychology and Behaviour, vol. 42, pp. 151-161, 2016.

[9] N. Dubovski, E. Ert, and M. Y. Niv, "Bitter mouth-rinse affects emotions," Food Quality and Preference, vol. 60, pp. 154-164, 2017.

[10] S. R. Jaeger, S. M. Lee, K.-O. Kim, S. L. Chheang, D. Jin, and G. Ares, "Measurement of product emotions using emoji surveys: c," Food Quality and Preference, vol. 62, pp. 46-59, 2017.

[11] M. Kirwan, S. M. Pickett, and N. L. Jarrett, "Emotion regulation as a moderator between anxiety symptoms and insomnia symptom severity," Psychiatry Research, vol. 254, pp. 40-47, 2017.

[12] D. Clingingsmith, "Negative emotions, income, and welfare: causal estimates from the PSID," Journal of Economic Behavior \& Organization, vol. 130, pp. 1-19, 2016.

[13] B. Q. Ford and I. B. Mauss, "Culture and emotion regulation," Current Opinion in Psychology, vol. 3, pp. 1-5, 2015.

[14] E. Vingilis, Z. Yıldırım-Yenier, P. Fischer et al., "Self-concept as a risky driver: m," Transportation Research Part F: Traffic Psychology and Behaviour, vol. 43, pp. 15-23, 2016.

[15] G. E. Kang and M. M. Gross, "The effect of emotion on movement smoothness during gait in healthy young adults," Journal of Biomechanics, vol. 49, no. 16, pp. 4022-4027, 2016.

[16] C. E. Gallagher, M. C. Watt, A. D. Weaver, and K. A. Murphy, “"I fear, therefore, I shop!" exploring anxiety sensitivity in relation to compulsive buying," Personality and Individual Differences, vol. 104, pp. 37-42, 2017.

[17] Y. L. Chen, C. L. Chang, and C. S. Yeh, "Emotion classification of YouTube videos," Decision Support Systems, vol. 101, 2017.

[18] K. N. Minhad, S. H. M. Ali, and M. B. I. Reaz, "Happy-anger emotions classifications from electrocardiogram signal for automobile driving safety and awareness," Journal of Transport \& Health, vol. 7, pp. 75-89, 2017.

[19] B. Reimer, B. Mehler, J. F. Coughlin, N. Roy, and J. A. Dusek, "The impact of a naturalistic hands-free cellular phone task on heart rate and simulated driving performance in two age groups," Transportation Research Part F: Traffic Psychology and Behaviour, vol. 14, no. 1, pp. 13-25, 2011.

[20] F. H. Wilhelm, J. A. Rattel, M. Wegerer et al., "Attend or defend? sex differences in behavioral, autonomic, and 
respiratory response patterns to emotion-eliciting films," Biological Psychology, vol. 130, pp. 30-40, 2017.

[21] E. Rendon-Velez, P. M. van Leeuwen, R. Happee, I. Horváth, W. F. van der Vegte, and J. C. F. de Winter, "The effects of time pressure on driver performance and physiological activity: a driving simulator study," Transportation Research Part F: Traffic Psychology and Behaviour, vol. 41, pp. 150-169, 2016.

[22] W. Handouzi, C. Maaoui, A. Pruski, and A. Moussaoui, "Objective model assessment for short-term anxiety recognition from blood volume pulse signal," Biomedical Signal Processing and Control, vol. 14, pp. 217-227, 2014.

[23] A. Goshvarpour, A. Abbasi, and A. Goshvarpour, "An accurate emotion recognition system using ECG and GSR signals and matching pursuit method," Biomedical Journal, vol. 40, no. 6, pp. 355-368, 2017.

[24] M. P. Barnard and P. Chapman, "The effects of instruction and environmental demand on state anxiety, driving performance and autonomic activity: are ego-threatening manipulations effective?" Transportation Research Part F: Traffic Psychology and Behaviour, vol. 55, pp. 123-135, 2018.

[25] K. Rymarcayk, C. Biele, A. Grabowska, and H. Majczynski, "EMG activity in response to static and dynamic facial expressions," International Journal of Psychophysiology, vol. 79, no. 2, pp. 330-333, 2011.

[26] B. Scott-Parker, "Emotions, behaviour, and the adolescent driver: a literature review," Transportation Research Part F: Traffic Psychology and Behaviour, vol. 50, pp. 1-37, 2017.

[27] Y. Ba, W. Zhang, A. H. S. Chan, T. Zhang, and A. S. K. Cheng, "How drivers fail to avoid crashes: a risk-homeostasis/perception-response (RH/PR) framework evidenced by visual perception, electrodermal activity and behavioral responses," Transportation Research Part F: Traffic Psychology and Behaviour, vol. 43, pp. 24-35, 2016.

[28] R. Takahashi, M. Kobayashi, T. Sasaki, Y. Yokokawa, H. Momose, and T. Ohhashi, "Driving simulation test for evaluating hazard perception: elderly driver response characteristics," Transportation Research Part F: Traffic Psychology and Behaviour, vol. 49, pp. 257-270, 2017.

[29] D. Herrero-Fernández, "Psychophysiological, subjective and behavioral differences between high and low anger drivers in a simulation task," Transportation Research Part F: Traffic Psychology and Behaviour, vol. 42, no. 2, pp. 365-375, 2016.

[30] I. Isikli Esener, "Subspace-based feature extraction on multiphysiological measurements of automobile drivers for distress recognition," Biomedical Signal Processing and Control, vol. 66, no. 5, Article ID 102504, 2021.

[31] V. Balasubramanian and R. Bhardwaj, "Can cECG be an unobtrusive surrogate to determine cognitive state of driver?" Transportation Research Part F: Traffic Psychology and Behaviour, vol. 58, pp. 797-806, 2018.

[32] C. Zhao, M. Zhao, J. Liu, and C. Zheng, "Electroencephalogram and electrocardiograph assessment of mental fatigue in a driving simulator," Accident Analysis \& Prevention, vol. 45, pp. 83-90, 2012.

[33] M. Gromer, D. Salb, T. Walzer, N. M. Madrid, and R. Seepold, "ECG sensor for detection of driver's drowsiness," Procedia Computer Science, vol. 159, pp. 1938-1946, 2019.

[34] M. Taherisadr, P. Asnani, S. Galster, and O. Dehzangi, "ECGbased driver inattention identification during naturalistic driving using mel-frequency cepstrum 2-D transform and convolutional neural networks," Smart Health, vol. 9-10, pp. 50-61, 2018.

[35] Y. Guo, X. Wang, Q. Xu, F. Liu, Y. Liu, and Y. Xia, “Changepoint analysis of eye movement characteristics for female drivers in anxiety," International Journal of Environmental Research and Public Health, vol. 16, no. 7, Article ID 1236, 2019.

[36] X. Wang, Y. Guo, C. Chen, Y. Xia, and Y. Liu, "Analysis of female drivers' ECG characteristics within the context of connected vehicles," Journal of Intelligent and Connected Vehicles, vol. 2, no. 2, pp. 55-66, 2019. 